\title{
Design and Experimental Microstrip MIMO Antenna for WLAN Applications
}

\author{
Shiddanagouda.F.B ${ }^{1}$, Vani.R.M' ${ }^{2}$, P.V. Hunugund ${ }^{1}$, Siva Kumar Swami ${ }^{3}$ \\ Department of Applied Electronics, Gulbarga University, Gulbarga, India ${ }^{1}$ \\ Department of University Science Instrumentation Centre, Gulbarga University, Gulbarga, India ${ }^{2}$ \\ Department of Electronics and Communication, Sphoorthy Engineering College, Hyderabad, India ${ }^{3}$
}

\begin{abstract}
In this article we presented simulated and fabricated MIMO (Multiple Input Multiple Output) antenna for WLAN applications. The designed MIMO antenna consist of four element microstrip patch antenna by using FR-4 substrate and proposed size of the four element MIMO antenna is $62.8 \mathrm{X} 60 \mathrm{X} 1.6 \mathrm{~mm}^{3}$. The antenna is fabricated and tested. Fabricated measured results are good in agreement with simulation results. The designed antenna resonated at $5.9 \mathrm{GHz}$ frequency and its isolation $-21.3 \mathrm{~dB}$ with overall bandwidth $204 \mathrm{MHz}$ and it supported data rate of $5 \mathrm{Gbps}$ with maximum correlation coefficient is less than 0.03 and VSWR is 1.2. The result of this proposed MIMO antenna system shows a good isolation, bandwidth, VSWR, and correlation coefficient, hence proposed antenna suited for WLAN applications.
\end{abstract}

Keywords: Microstrip patch antenna, MIMO, WLAN.

\section{INTRODUCTION}

The demand for higher data rates in wireless communications due to extensive use of multimedia applications and video streaming is always on the rise. With the limited spectrum and power levels available for current wireless standards, the multiple-input-multiple-output (MIMO) technology was adopted to provide a significant increase in such data rates via the use of multiple antennas on the user and base station terminals. The design of MIMO antenna systems on the user handset has many challenges due to the limited size and complexity. These challenges become even more profound when antenna systems are to cover lower frequency bands supported by the latest LTE standards with multiband coverage. Wireless local area network (WLAN) and Worldwide Interoperability for Microwave Access (WiMAX) have been widely used in mobile devices such as handheld computers, laptops and intelligent phones [1-3]. This antenna has been widely considered as a cost-effective, reliable and high-speed data connectivity which enables user mobility.

For this reason, plenty of MIMO antennas for mobile communications have been investigated recent years [5-8]. However, most of the proposed MIMO antennas have narrow impedance bandwidth and low isolation. In this work we proposed high isolation and wide bandwidth of four element rectangular microstrip patch MIMO antenna to resonate $5.9 \mathrm{GHz}$ for WLAN applications. Microstrip patch antenna preferable due to its easy fabrication low cost, small size low weight, integrate ability compatibility with standard manufacturing process and the smallest edge-to-edge separation of the four symmetrical patch antennas is $\lambda / 4$ (where $\lambda$ is the free space wavelength), because if the antenna are placed close to each other, resulting in high correlation between the antenna elements, and therefore poor diversity. Hence the proposed four element MIMO antenna exhibiting the wide bandwidth of $204 \mathrm{MHz}$ with supporting data rate $5 \mathrm{Gbps}$ and proposed antenna results shows that it well suited for WLAN applications and finally we discussed some of the better solutions to overcome the critical issues of MIMO antenna design problems.

\section{MIMO ANTENNA DESIGN PROCEDURE}

The single antenna element, the geometry of an antenna element is optimized and is shown in Figure 1. The FR-4 $\left(\varepsilon_{\mathrm{r}}=4.4\right)$ single substrate is used with $1.6 \mathrm{~mm}$ thickness. Rectangular shape patch antenna is use to provide the WLAN applications and the single antenna dimension are shown in table1. Figure.2 shows that the reflection coefficient S11 is $-21.3 \mathrm{~dB}$ at $5.9 \mathrm{GHz}$. Reflection coefficient is a measurement of how much power the antenna accepts from the transmission line the impedance of the antenna must match the impedance of the transmission line for maximum power transfer. Hence the single antenna has shown good isolation with a frequency bandwidth of 204MHz (WLAN frequency band). Figure. 3 shows the meandering of the surface current on the radiating rectangular patch, Figure.4 shows that the gain is better than $4 \mathrm{dBi}$ with antenna efficiency of $93.43 \%$ at $5.9 \mathrm{GHz}$. The results of single rectangular patch antenna are summarized in table 2. 
UGC Approved Journal

IJIREEICE

International Journal of Innovative Research in Electrical, Electronics, Instrumentation and Control Engineering

ISO 3297:2007 Certified

Vol. 5, Issue 7, July 2017

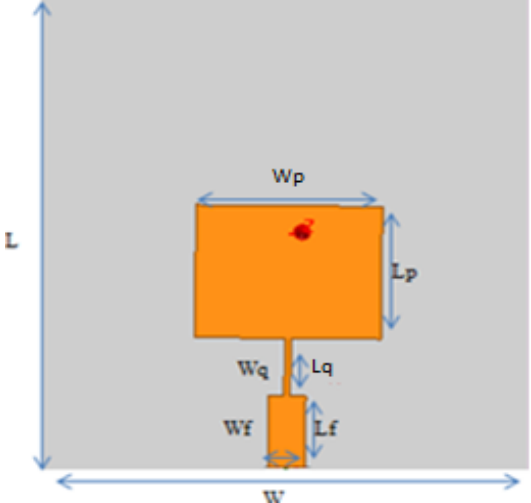

Figure1: Geometry of Single Antenna

\begin{tabular}{|l|c|}
\hline Parameters & $\begin{array}{l}\text { Dimensions } \\
(\mathrm{mm})\end{array}$ \\
\hline Width of the Patch Wp & 11.35 \\
\hline Length of the Patch Lp & 15.25 \\
\hline Width of the Quarter wave transformer Wq & 3.05 \\
\hline Length of the Quarter wave transformer Lq & 6.15 \\
\hline Width of the feed line Wf & 0.5 \\
\hline Length of the feed line Lf & 4.9 \\
\hline
\end{tabular}

Table1: Single Antenna Dimensions

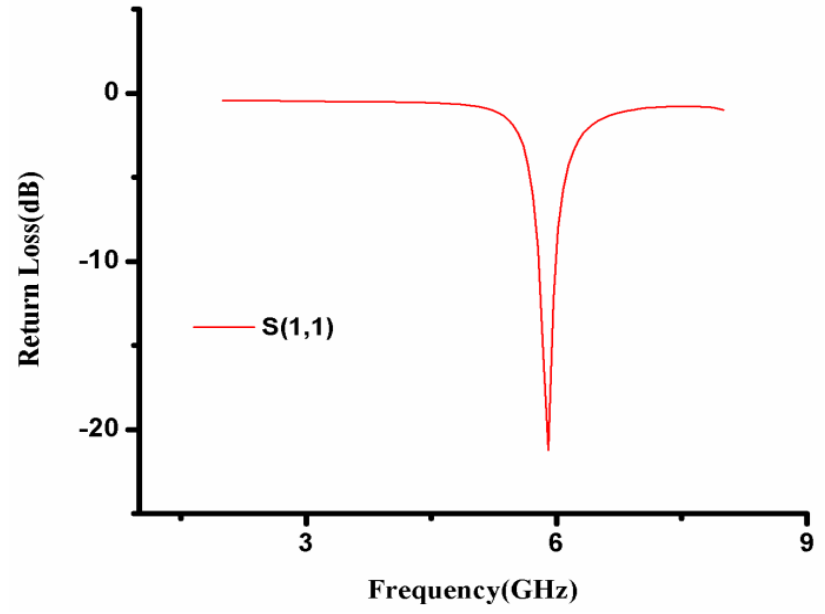

Figure2: Reflection Coefficient of Single Antenna

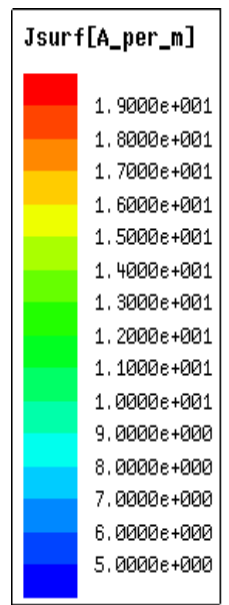

Figure3: Surface current of Single Antenna

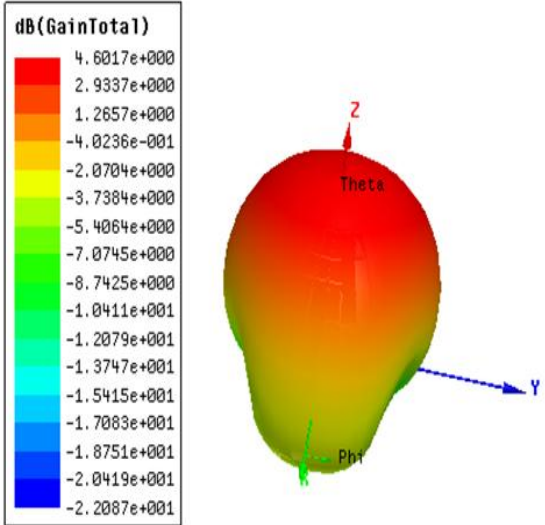

Figure 4: Gain of Single Antenna

\begin{tabular}{|l|l|}
\hline Parameters & Results \\
\hline Return Loss & $-21.3 \mathrm{~dB}$ \\
\hline Surface Current & 1.9 \\
\hline Gain & $4.60 \mathrm{~dB}$ \\
\hline Efficiency & $93.43 \%$ \\
\hline Bandwidth & $204 \mathrm{MHz}$ \\
\hline
\end{tabular}

Table 2: Summarized Single Antenna Results

For the 2x2 MIMO antenna dimension parameters and geometry are shown in table 3 and Figure 5 respectively. The $2 \times 2$ MIMO antennas with edge to edge separation of $\lambda / 4$ (where $\lambda$ is the free space wavelength) maintained because if the antennas are placed close to each other, resulting in high correlation between the antenna elements, and therefore poor diversity and separate feeding ports for all individual antennas.

Figure.6 shows the reflection coefficients S11, S22 S33, and S44 is $-21.3 \mathrm{~dB}$ at $5.9 \mathrm{GHz}$ with a frequency bandwidth of $204 \mathrm{MHz}$ (WLAN frequency band). Hence the proposed 2X2 MIMO antenna without increasing bandwidth it supported data rate is $5 \mathrm{Gbps}$ as per the Shannon channel capacity. Figure.7 shows that the gain is better than 5.69dBi with antenna efficiency of $98.03 \%$ at $5.9 \mathrm{GHz}$. Figure 8 shows that the coupling between ports 1 and 2 is better than $-20.9 \mathrm{~dB}$ at $5.9 \mathrm{GHz}$. Figure. 9 shows the meandering of the surface current on the proposed MIMO antenna. 
UGC Approved Journal

IJIREEICE

International Journal of Innovative Research in Electrical, Electronics, Instrumentation and Control Engineering

ISO 3297:2007 Certified

Vol. 5, Issue 7, July 2017

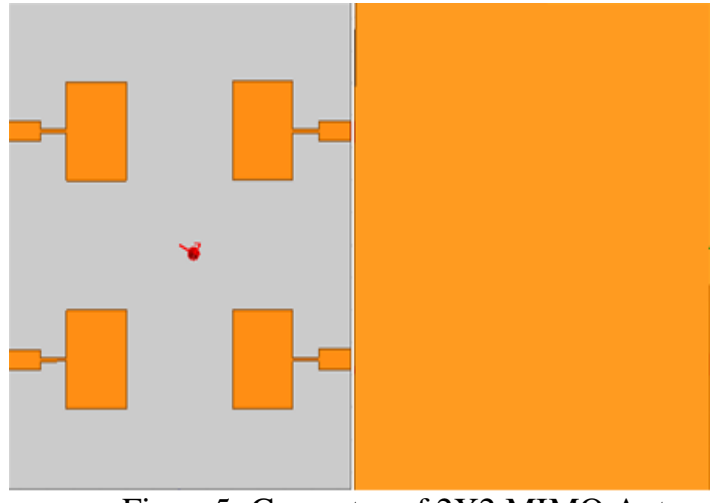

Figure5: Geometry of 2X2 MIMO Antenna

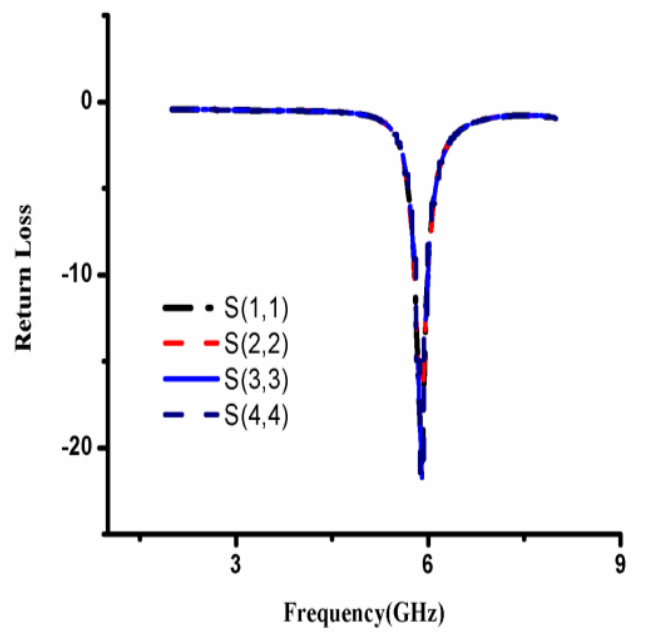

Figure 6: Return loss of MIMO antenna

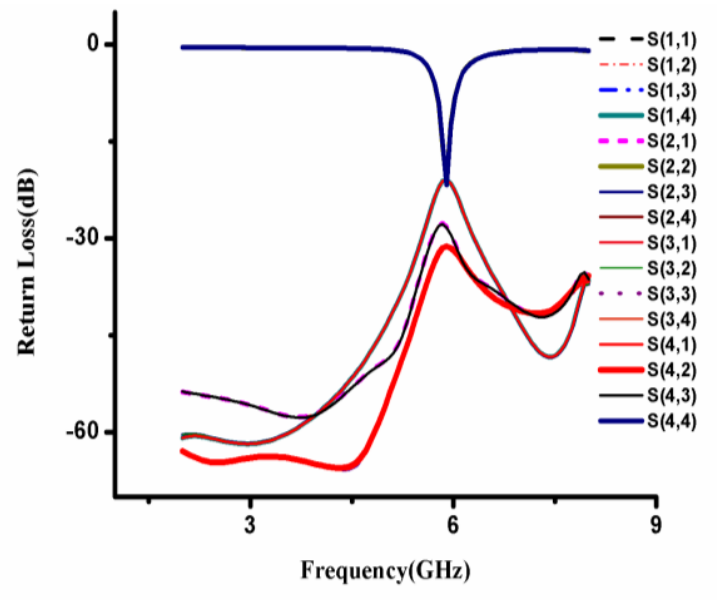

Figure 8: Mutual Coupling of MIMO antenna

\begin{tabular}{|l|c|}
\hline Parameters & Dimensions $(\mathrm{mm})$ \\
\hline Length of the substrate & 62.8 \\
\hline Width of the substrate & 60 \\
\hline Antenna between edge separation & $\lambda / 4$ \\
\hline Height of the substrate & 1.6 \\
\hline
\end{tabular}

Table 2: 2X2 MIMO Antenna Dimension

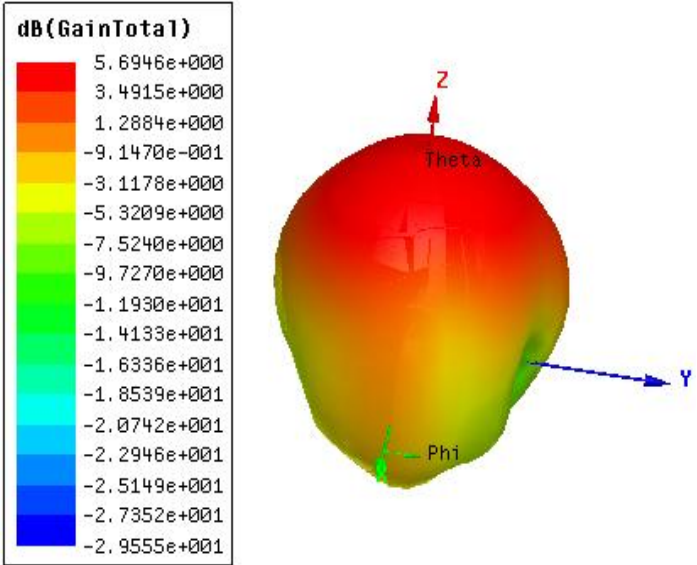

Figure 7: Gain of MIMO antenna

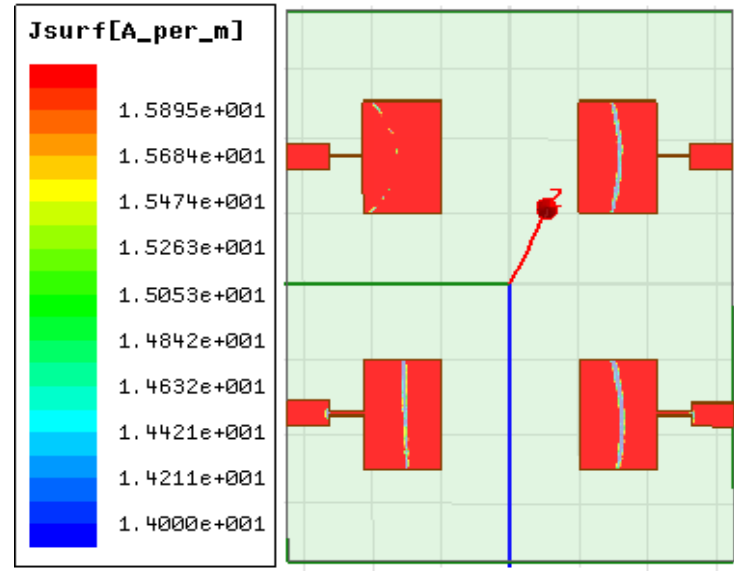

Figure 9: Surface Current of MIMO antenna

\section{III.FABRICATED AND MEASURMENT MIMO ANTENNA}

Figure 10 and Figure 11 show the fabricated single element and 2X2 MIMO antennas respectively. Figure 12 shows that the single antenna measured reflection coefficient S11 is equal to $-21.3 \mathrm{~dB}$ at $5.9 \mathrm{GHZ}$ with a band width of $204 \mathrm{MHz}$ hence good agreement achieved between the measured and the simulated results for the single element. Figure 13 shows that the 2X2 MIMO antennas measured reflection coefficients of S11, S22 S33, and S44 are $-21.3 \mathrm{~dB}$ at $5.9 \mathrm{GHz}$ with a frequency bandwidth of $204 \mathrm{MHz}$ (WLAN frequency band). Hence good agreement achieved between the measured and simulated results for the 2X2 MIMO antenna. 
UGC Approved Journal

IJIREEICE

Vol. 5, Issue 7, July 2017

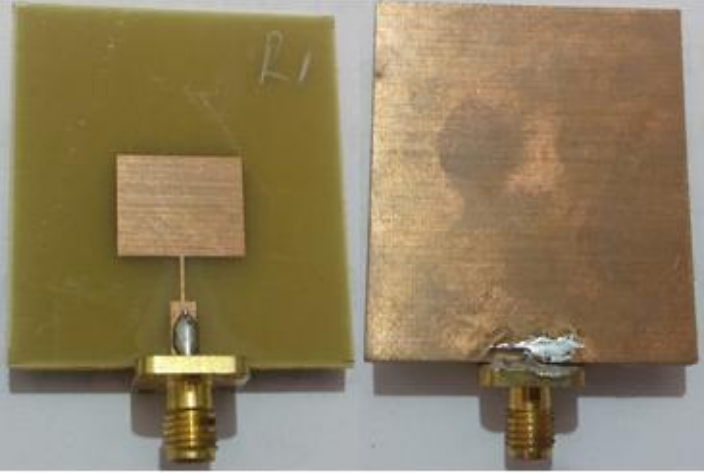

Figure 10: Fabricated Single Antenna

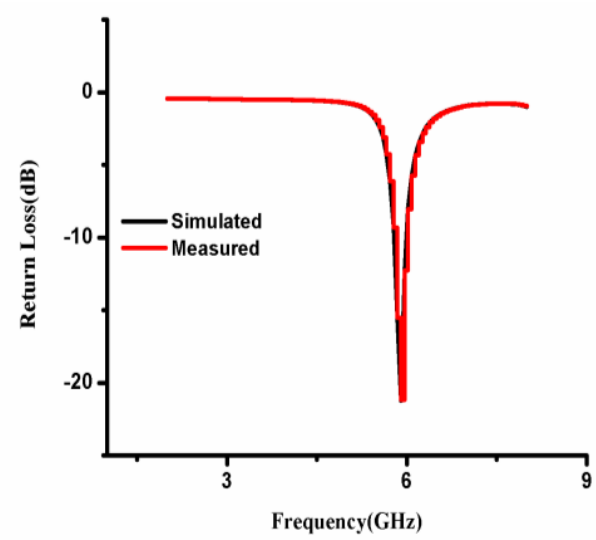

Figure11: Return loss of fabricated single Antenna

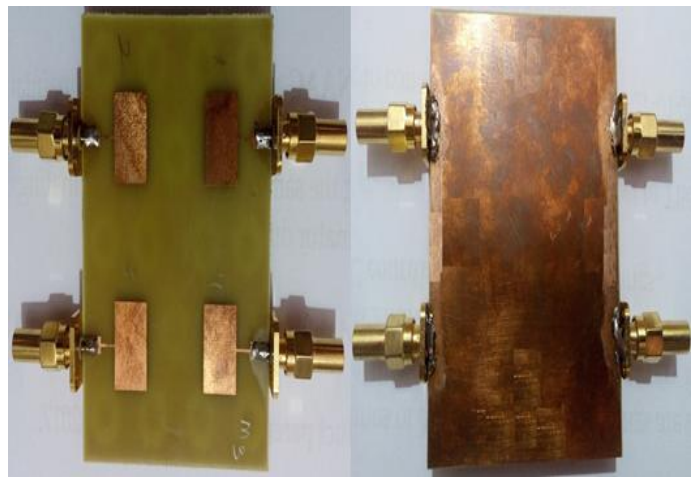

Figure 11: Fabricated 2X2 MIMO Antenna

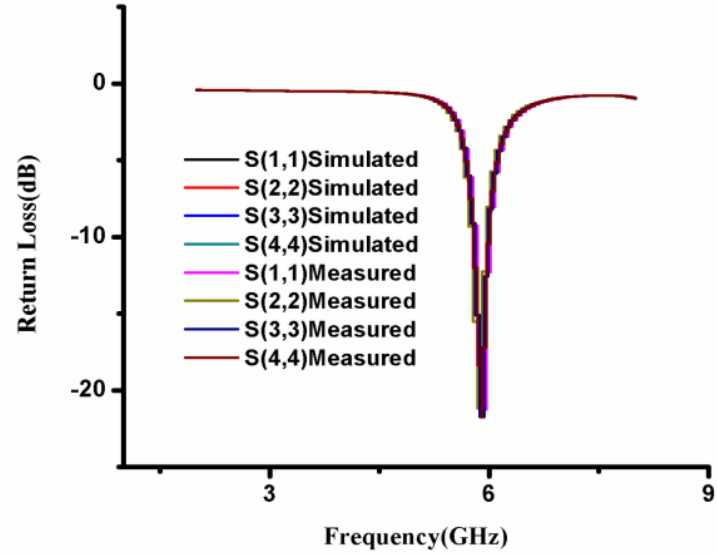

Figure 12: Return loss of fabricated 2X2 MIMO Antenna

Figure 13 shows VSWR of 2X2 MIMO antenna is less than 1.2 hence it shown good amount of power transfer along the antennas. Figure 14 shows correlation coefficient is less than 0.001 hence we concluded that very small channel capacity loss in the rich environment of multipath.
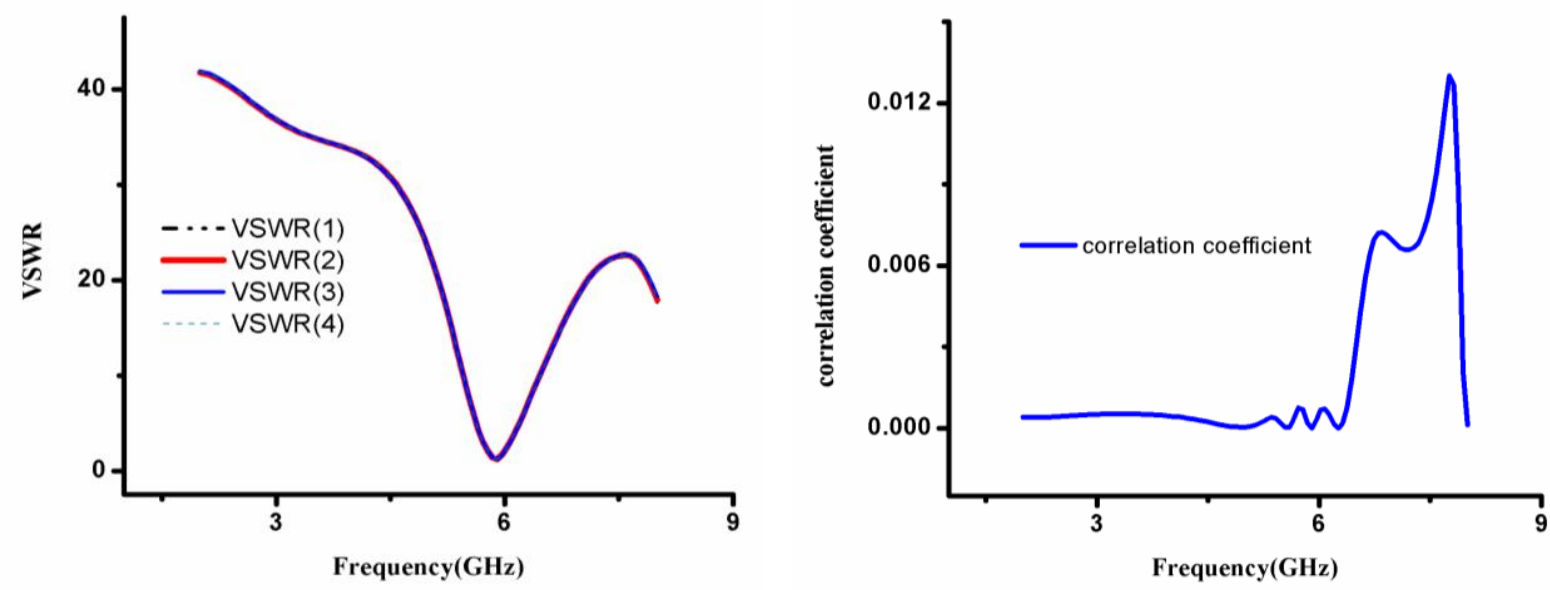

Figure13: VSWR of 2X2 MIMO antenna

Figure 14: Correlation Coefficients of 2X2 MIMO Antenna

\section{IV.CONCLUSION}

A proposed rectangular microstrip patch array antenna that is suitable for the MIMO 4G and 5G WLAN has been developed. Single element and 2X2 MIMO antennas prototype are fabricated and measured. Good agreement between the measured and simulated results is achieved. The achieved results satisfy the requirements of both the MIMO $4 \mathrm{G}$ and 5G WLAN systems. 
UGC Approved Journal

IJIREEICE

International Journal of Innovative Research in Electrical, Electronics, Instrumentation and Control Engineering

ISO 3297:2007 Certified

Vol. 5, Issue 7, July 2017

\section{ACKNOWLEDGMENT}

The authors would like to convey thanks to the department of science \& technology (DST) government of India, New Delhi, for sanctioning research facility to Department of Applied Electronics Gulbarga University Gulbarga under FIST project

\section{REFERENCES}

[1] C.A. Balanis. "Antenna Theory: Analysis and Design ". 2nd Ed, United States of America, John Wiley \& Sons, $0471592684,1982 . c h .14$.

[2] J. Huang, "A review of antenna miniaturization techniques for wireless applications," Jet Propulsion Laboratory, California Institute of Technology, 2001

[3] A C.C Chiau, X chenn and C.G. parini "A compact four element diversity antenna array for PDA terminals in a MIMO system" Microw Opt Technol let..vol 44, pp. 408-412, Mar 2005.

[4] R.B. Waterhouse, S. D. Targonski, D. M. Kokotoff, "Design and performance of small printed antennas," IEEE trans. Antennas, 1998

[5] K.L. Wang, C.H.Chang B.Chen S.Yang "Three Antenna MIMO system for WLAN operation in a PDA phone "Microw Opt Technol let.vol 48, pp. 1238-1242, Jul 2006.

[6] Y W chi and K.L.Wong "Internal compact dual-band printed loop antenna for mobile phone application "IEEE Trans antenna propag..vol.55, pp.1457-1462 May 2007.

[7] Hyundong Shin and Jae Hong Lee, "Capacity of Multiple Antenna Fading Channels: Spatial Fading Correlation, Double Scattering and Keyhole,"IEEE Transactions on Information Theory, 49, 10, October 2003, pp.2636-2647.

[8] A.A. Asaker, R.S. Ghoname, A.A. Zekry, " Design of a Planar MIMO Antenna for LTE-Advanced "International Journal of Computer Applications (0975 - 8887)Volume12,april2015.

[9] Foschini, G. J. and M. J. Gans, "On limits of wireless communications in a fading environment when using multiple antennas," Wirel. Pers. Commun., Vol. 6, No. 3, 311-335, 1998.

[10] M. A. Jensen, J. W. Wallace, "A review of antennas and propagation for MIMO wireless communications", IEEE Trans. Antennas Propagation., vol. 52, pp. 2810-2824, Nov. 2004

[11] T. Svantesson. On the Capacity and Correlation of Multi-Antenna Systems Employing Multiple Polarizations. Proceedings of IEEE Antennas and Propagation Symposium vol. 3, pp. 202-205, June 2002

\section{BIOGRAPHIES}

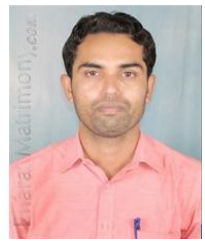

Shiddanagouda.F.B received his BE and M.Tech from PES College of Engineering Mandya and IIT Kharagpur in the year 2009 and 2012 respectively. He has published more than 10 papers in national and international journals. Currently he is pursuing his Ph.D. in the field of Microwave Antennas from the department of Applied Electronics, Gulbarga University Gulbarga. India.

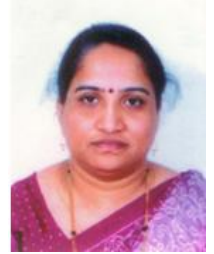

Vani.R.M received her BE and M.Tech from BIET Davangere and S.J.C.E Mysore, Karnataka. She has received her Ph.D. in Applied Electronics Gulbarga University Gulbarga, India in the year 2005. She is working as Head, University Science Instrumentation Centre, Gulbarga University Gulbarga. She has more than 85 research publications in national and international reputed journals. She presented the research paper in national and international conference in India and abroad. She has conducted several courses, workshops, for the benefits of faculties and field engineers. Her area of interests are microwave antennas, PC based instrumentation, embedded controllers and wireless communication. She has one UGC major research project in her credit.

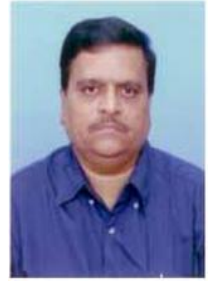

P.V.Hunugund received his M.Sc. and Ph.D. from Department of Applied Electronics Gulbarga University Gulbarga India, in the year 1982, and 1992 respectively. He is working as a Professor and chairman of Applied Electronics Department Gulbarga University Gulbarga. He has published more than 100 research papers in national and international reputed journals. He presented more than 30 research paper in national and international conference in India and abroad. He has guided many M.Phil, and Ph.D. students. His area of interests are microwave antennas, and wireless communication systems. He has three major research projects in his credits

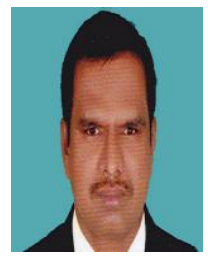

Siva Kumar Swamy.K awarded M. Tech in 2002 from JNTU Hyderabad and, PhD in 2010 from JNTU Anthapur. He has rich experience in Teaching, Research, and administration. He has 30 Papers published in International/National Journals. His areas of interest are Microwave antenna, Signal Processing and image processing. 